\title{
MANUFACTURING AND MECHANICAL PROPERTIES OF A LARGE SIZE ALLOY 706 DISK BY ESR PROCESS
}

\author{
T.Honjo, O.Matsumoto, K.Morita, K.Hirose and M.Okamura \\ Steel Casting \& Forging Plant, Kobe Steel Ltd. \\ Shinhama 2-3-1, Arai-cho, Takasago, 676, Japan
}

\begin{abstract}
A large Ni-base superalloy 706 disk for advanced gas turbines was trial manufactured and evaluated. Preliminary studies of hot workability, homogenizing treatment and grain refining conditions were made before trial manufacturing. On the basis of these results, trial disk forging with $1900-\mathrm{mm}$ diameter and $310-\mathrm{mm}$ thickness was successfully carried out using electroslag remelted ingot $810-\mathrm{mm}$ in diameter and weighing 10-tons. Ultrasonic and metallographic investigation, and tensile, impact, fatigue and fracture toughness testing were conducted. No macrosegregations and uniform grain structure ASTM G.S.No. 3.2 3.8 were observed in the disk. With ultrasonic testing, the minimum detectable defect size (MDDS) was 2.4-mm in diameter as a flat bottom hole. Observed tensile properties were satisfactory with the AMS5703 (Aero Space Materials specifications), and fatigue and fracture toughness properties were equivalent to those of smaller size forgings of 706 alloy.
\end{abstract}

\footnotetext{
Superalloys 718, 625, 706 and Various Derivatives Edited by E.A. Loria
}

The Minerals, Metals \& Materials Society, 1994 


\section{Introduction}

Increased firing temperatures have helped the fuel efficiency of gas turbine based power generation systems. Very large Ni-base superalloy 706 disks are currently fabricated for advanced gas turbines developed by General Electric Company(1), because of their excellent mechanical properties at elevated temperatures relative to other high alloyed steels. D.Rayne and J.F.Uginet (2) reported on the large 706 alloy turbine disks forged from triple melted ingot-vacuum induction melting (VIM) plus electroslag remelting (ESR) and vacuum arc remelting (VAR). Studies of large size 706 disk forged from ESR and/or VAR ingots have been reported by H.L.Eiselstein (3), and by A.M.Johnson and K.E.Fritz (4) for gas turbine applications. For cryogenic applications, studies of large 706 forgings melted by the ESR process were also reported by Hooper et al (5) and Matsumoto et al (6). The purpose of this work is to determine optimum manufacturing conditions for large forgings, and to evaluate the properties of the large trial disk melted by the ESR process for advanced gas turbine applications. This paper describes the results of preliminary studies of the manufacturing process, especially homogenization and grain refining, and the metallugical and mechanical properties of large trial disk forging.

\section{Preliminary Study}

Hot workability, homogenizing treatment and grain size refining conditions were investigated using an alloy 706 billet forged from a 2-ton ESR ingot. Table I shows the chemical composition of the billet.

Table I Chemical compositions of Alloy 706 2-ton ESR billet

(wt \%)

\begin{tabular}{|llllllllllll|}
\hline $\mathrm{C}$ & $\mathrm{Si}$ & $\mathrm{Mn}$ & $\mathrm{P}$ & $\mathrm{S}$ & $\mathrm{Ni}$ & $\mathrm{Cr}$ & $\mathrm{Ti}$ & $\mathrm{Al}$ & $\mathrm{Nb}$ & $\mathrm{B}$ & $\mathrm{Fe}$ \\
\hline 0.04 & 0.17 & 0.21 & 0.006 & 0.002 & 43.0 & 16.2 & 1.67 & 0.15 & 3.07 & 0.0044 & Bal. \\
\hline
\end{tabular}

\section{$\underline{\text { Homogenizing Treatment }}$}

In alloy 706 , the precipitation hardening elements, $\mathrm{Nb}$ and $\mathrm{Ti}$, are segregated mainly at the interdenritic region. Because this microsegregation leads to precipitation of the brittle phase such as the Laves phase, it is desirable to reduce the microsegregation to obtain homogeneous mechanical properties in the whole product. The effect of the segregation ratio of $\mathrm{Nb}$ and $\mathrm{Ti}$ on the homogenizing treatment at the temperature range from $1100{ }^{\circ} \mathrm{C}$ to $1200{ }^{\circ} \mathrm{C}$ for 24 hours was investigated. Figure 1 shows the segregation ratio of $\mathrm{Nb}$ and $\mathrm{Ti}$ decrease as the homogenizing temperature increased. Maximum and minimum weight percent in the microsegregation of $\mathrm{Nb}$ and $\mathrm{Ti}$ were analysed by electron probe micro-analyzer, before and after homogenizing treatment. Each value was represented by $\mathrm{C}_{\mathrm{m}_{\max }}, \mathrm{C}_{\mathrm{min}}, \mathrm{C}_{\max }$ and $\mathrm{C}_{\min }$, respectively. It is clear that the segregation ratio of $\mathrm{Nb}$ and $\mathrm{Ti}$ are just under half of the initial ratio at above $1150{ }^{\circ} \mathrm{C}$.

\section{Hot Workability}

Tensile tests at the temperature range from 800 to $1200{ }^{\circ} \mathrm{C}$ were performed to investigate 
the optimum temperature range during the forging process. Test pieces were taken from the surface and center in the billet, and homogenized at $1100{ }^{\circ} \mathrm{C}, 1150{ }^{\circ} \mathrm{C}$ and $1200{ }^{\circ} \mathrm{C}$ for 24 hours before testing, respectively. Figure 2 shows the relation between test temperature and reduction of area. The results show that good workability could be obtained at a temperature range of 850 to $1150^{\circ} \mathrm{C}$ in alloy 706 . However, at around $1200^{\circ} \mathrm{C}$, rapid ductility drop due to the grain boundaries liquation is observed.

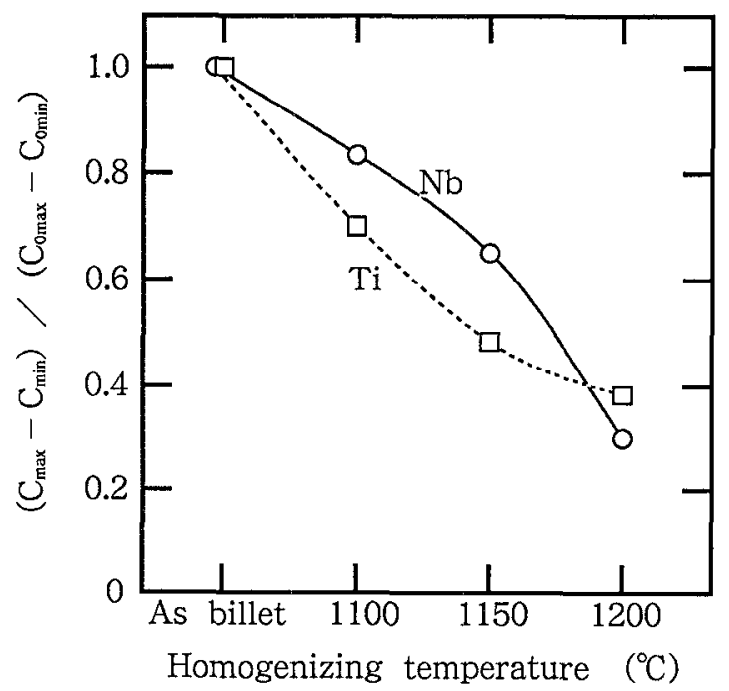

Figure 1 Effect of $\mathrm{Nb}$ and $\mathrm{Ti}$ segregation ratio on temperature in alloy 706

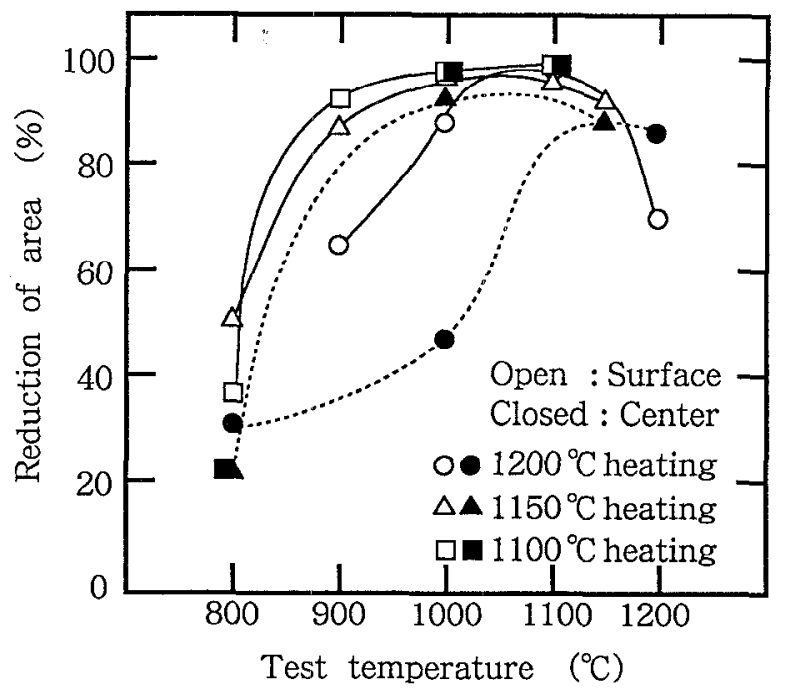

Figure 2 Hot workability of alloy 706 billet

\section{Grain Size Refining}

Ductility, strength, stress rupture properties, fatigue properties and ultrasonic permeability are strongly related to the grain size of superalloy forgings. Grain refinement occurs as a result of nucleation and growth of recrystallized grain during forging and solution heat treatment. The effect of grain size on the deformation ratio and temperature, and the heating 
temperature in the final forging process in 706 alloy were investigated using a Formaster Press. The heating temperatures of the specimens were selected at $1100{ }^{\circ} \mathrm{C}$ and $1050{ }^{\circ} \mathrm{C}$ before deformation and the applied strain rate was $0.001 / \mathrm{sec}$. The initial grain size of each specimen was ASTM No. 0 and 1.5 ,respectively. The solution heat treatment temperature after deformation was $980^{\circ} \mathrm{C}$. Figure 3 shows the relationship between grain size number and deformation conditions after solution heat treatment. The fine grain could be obtained by applying a higher strain at just above $950{ }^{\circ} \mathrm{C}$ in 706 alloy. These results indicate that finer grain can be obtained to finish the final forging at more than the recrystallization temperature. The grain size number had no effect on the heating temperatures. When a deformation ratio of lower than $20 \%$ is applied, the grain structure has the tendency to become homogeneous at lower heating temperatures. Therefore, finer grain sizes can be obtained in 706 forging through a combination of a lower heating temperature, higher deformation of more than 20 $\%$ and a controlled finish forging temperature of just above $950{ }^{\circ} \mathrm{C}$ during the final forging process.

a) Heating temperature of $1050^{\circ} \mathrm{C}$

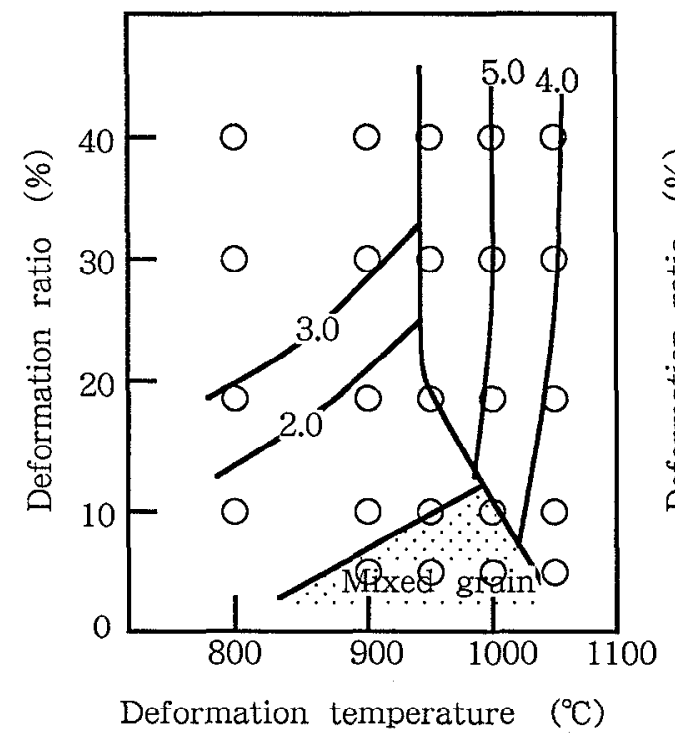

b) Heating temperature of $1100^{\circ} \mathrm{C}$

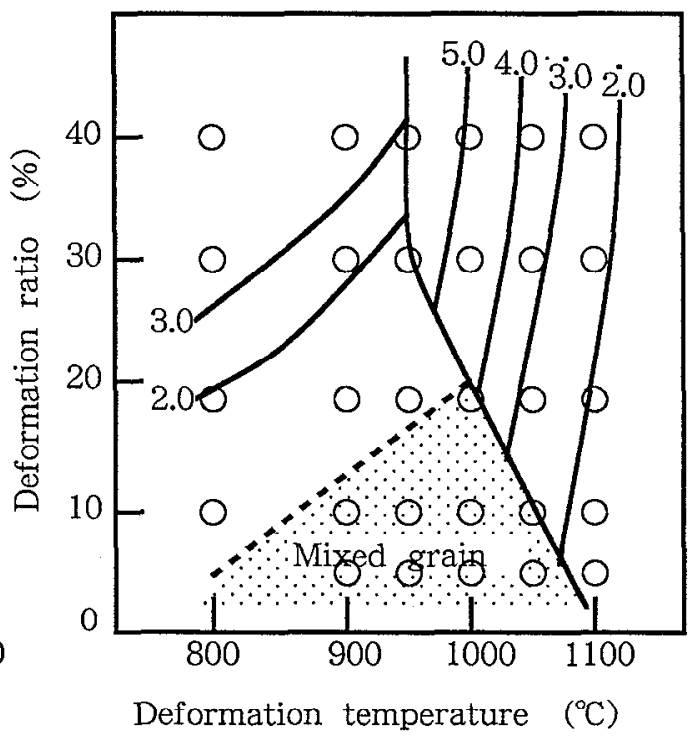

Figure 3 Effect of deformation temperature and strain on grain size number in alloy 706 after solution heat treatment.

\section{Forging Large Size Trial Disk}

On the basis of the above preliminary studies, manufacturing of trial disk was carried out. A large 706 ingot with an $810-\mathrm{mm}$ diameter which weighed 10 tons was produced by the ESR process, in which the electrode was refined using an electric arc furnace (EAF) and ladle furnace (LF). The ESR ingot was homogenized at $1170{ }^{\circ} \mathrm{C}$ after billet forging, and forged into a disk configuration with a $1900-\mathrm{mm}$ diameter and $310-\mathrm{mm}$ thickness after drawing and upsetting using a 13000-ton capacity press. The final forging operation was carried out by a step by step die forging process by which a fine grain structure was obtained. The disk forging was heat treated by 2 -step heat treatment as follows. 
Solution treatment : $960^{\circ} \mathrm{C}-4 \mathrm{hr} / \mathrm{OQ}$

Aging treatment : $730^{\circ} \mathrm{C}-8 \mathrm{hr} / \mathrm{FC}$ to $620^{\circ} \mathrm{C} / 620^{\circ} \mathrm{C}-8 \mathrm{hr} / \mathrm{AC}$

Figure 4 shows the appearance of the disk forging just after machining.

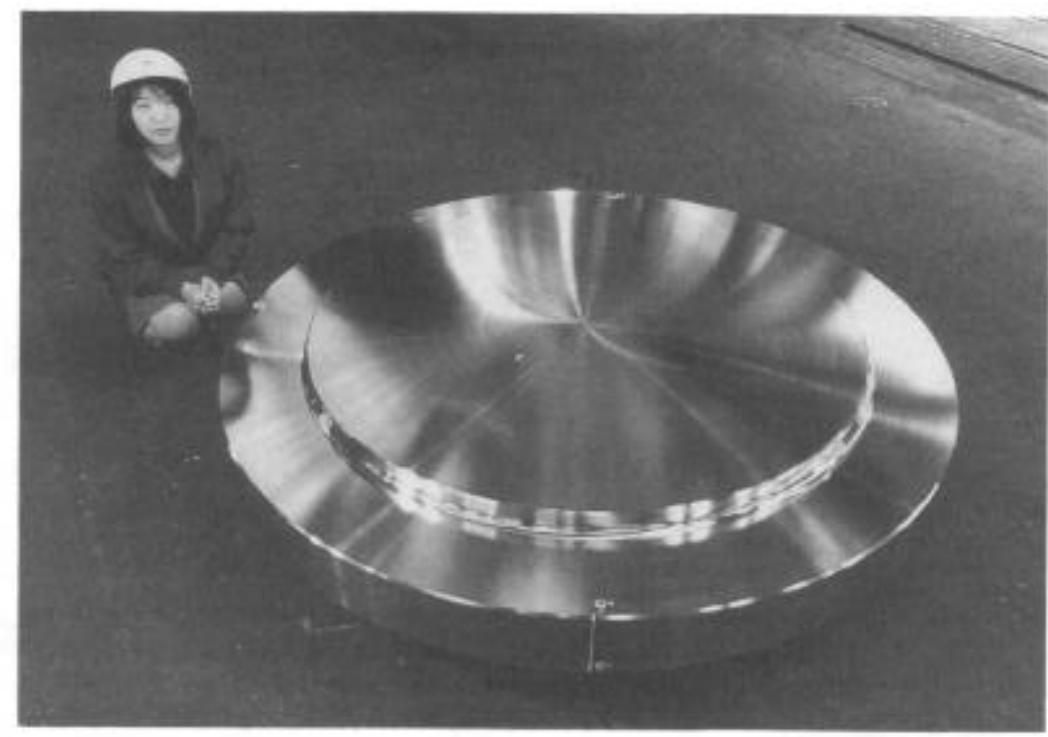

Figure 4 Appearance of the trial disk forging just after machining

\section{Characteristics of Large Size Alloy 706 Disk Forging}

\section{$\underline{\text { Ultrasonic Evaluation }}$}

The disk sections were ultrasonically tested using a $2.25 \mathrm{MHz}$ crystal, and no indications were found in the whole section. Table II shows the ultrasonic attenuation and the minimum detectable defect size as a flat bottom hole in the rim, mid-radius and center portion of the disk. This result shows that a flat bottom hole defect equivalent to more than 2.4-mm was detectable in the trial disk.

\section{Chemical Composition}

The chemical composition of various portions of the disk was presented in Table III . Observed values meet the requirement of AMS 5703 specifications and a uniform distribution of elements was obtained.

\section{$\underline{\text { Macro and Microstructures }}$}

When the ESR ingot was pre-forming to a billet, the top portion of the billet was cut off and machined and macro-etched in the transverse section. Figure 5 shows a photograph of the macro-etched structure and no macrosegregations such as freckles were observed. Figure 6 shows typical microstructures at the rim, mid-radius and center portion of the disk. They were fully recrystallized and have $3.2 \sim 3.8$ in ASTM grain size number. It is clear that fine and uniform grain structures are obtained in spite of large size 706 forging relative to other large superalloy forgings (3),(6). 
Table II Distribution of the ultrasonic attenuation coefficients and the minimum defect detectable size (MDDS)

\begin{tabular}{|c|c|c|}
\hline Locations & $\left\{20 \log \left(\mathrm{B}_{1} / \mathrm{B}_{2}\right)-6\right\} / 2 \mathrm{t}(\mathrm{dB} / \mathrm{cm})$ & MDDS $(\mathrm{mm} \phi \mathrm{FBH})$ \\
\hline Rim & 0.093 & 1.4 \\
\hline Mid - radius & 0.088 & 1.8 \\
\hline Center & 0.132 & 2.4 \\
\hline
\end{tabular}

Table III Distribution of chemical compositions in Alloy 706 disk forging (wt \%)

\begin{tabular}{|c|cccccccccccc|}
\hline Locations & $\mathrm{C}$ & $\mathrm{Si}$ & $\mathrm{Mn}$ & $\mathrm{P}$ & $\mathrm{S}$ & $\mathrm{Ni}$ & $\mathrm{Cr}$ & $\mathrm{Ti}$ & $\mathrm{Al}$ & $\mathrm{Nb}$ & $\mathrm{B}$ & $\mathrm{Fe}$ \\
\hline Rim & 0.008 & 0.09 & 0.07 & 0.006 & 0.001 & 41.19 & 15.81 & 1.66 & 0.15 & 2.82 & 0.0033 & $\mathrm{Bal}$. \\
\hline $\begin{array}{c}\text { Mid- } \\
\text { radius }\end{array}$ & 0.009 & 0.09 & 0.07 & 0.006 & 0.001 & 41.20 & 15.81 & 1.67 & 0.13 & 2.83 & 0.0033 & $\mathrm{Bal}$. \\
\hline Center & 0.009 & 0.09 & 0.07 & 0.006 & 0.001 & 41.28 & 15.80 & 1.73 & 0.14 & 2.90 & 0.0033 & $\mathrm{Bal}$. \\
\hline
\end{tabular}

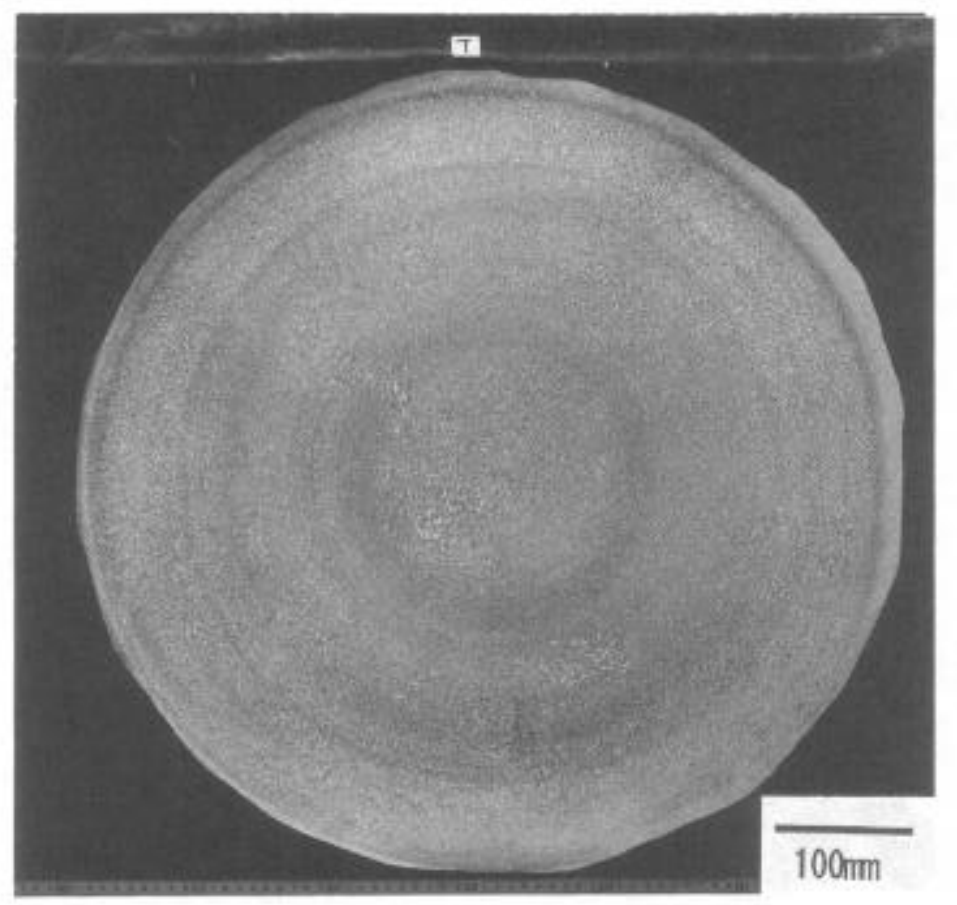

Figure 5 Transverse macroetched structure of alloy 706 billet 

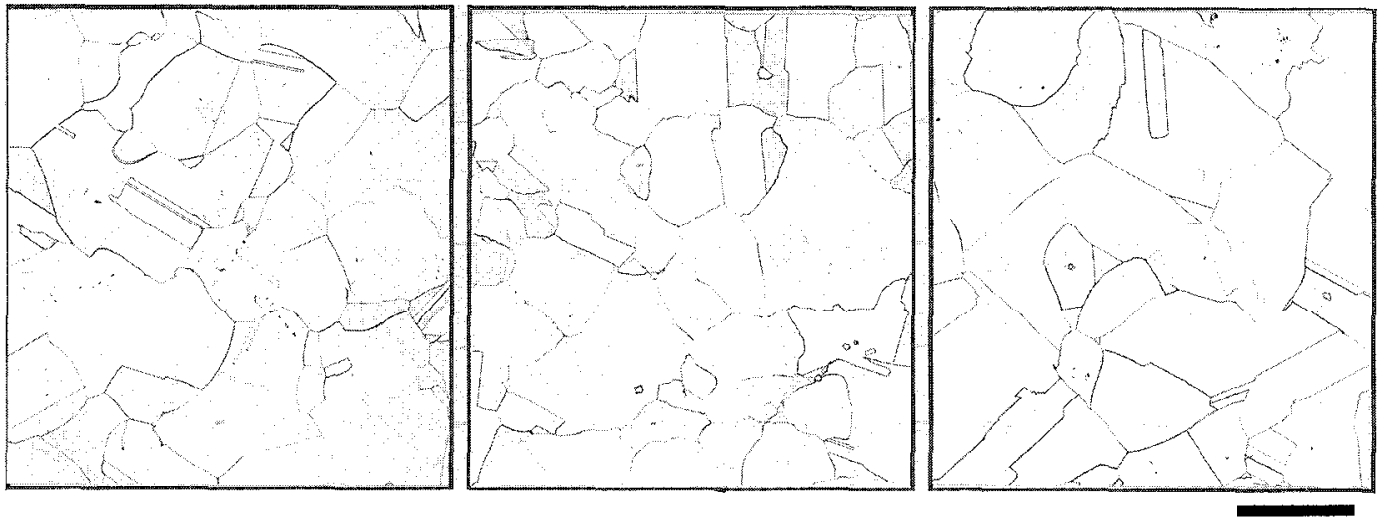

$100 \mu \mathrm{m}$

Figure 6 Optical microstructures of Alloy 706 disk forging

\section{$\underline{\text { Tensile and Impact Properties }}$}

Tensile tests werc conducted at a temperature range from room temperature to $600{ }^{\circ} \mathrm{C}$ using tangential-direction test specimens at the rim, mid-radius and center portion of the disk. Charpy impact tests at room temperature were also conducted. Tensile properties and absorbed energy at room temperature are given in Table IV. Figure 7 shows the tensile propcrties at the elevated temperatures. The yield and tensile strength in the center portion were higher than in the rim portion, and tensile ductility (elongation and reduction of area) and absorbed energy in the center portion were lower than in the rim portion. It is considered that these results has related to the difference sizes in the dendritic structure between the surface and center portions of the ESR ingot. However, all observed values of the tensile tests met the requirements of the AMS 5703 specifications.

\section{Low and High Cycle Fatigue Properties}

Low cycle fatigue tests were performed at room temperature under the conditions of trianguler wave form and a $0.2 \% / \mathrm{sec}$ in strain rate using center-radial test pieces. Figure 8 shows the relation between applied strain and the number of cycles to failure at room temperature. High cycle fatigue tests were performed by the rotating bending method at room temperature. The fatigue strength at $10^{7}$ cycles was approximately $330 \mathrm{MPa}$ at room temperatures as shown in Figure 9. The fatigue strength- tensile strength ratio, 0.3 was equivalent to that of smaller size disks of 706 alloy(7).

\section{Fracture Toughness Properties}

Fracture toughness tests were conducted at room temperature in accordance with ASTM E813-81. The 1CT compact tension specimens with the L-R direction were removed at the rim, mid- radius and center portion in the disk. Fracture toughness values were obtained by means of the elastic plastic $\left(\mathrm{J}_{\mathrm{IC}}\right)$ fracture criterion and associated resistance curve test techniques (8). All obtained values are listed in Table V. There are little difference in the each portions, and are comparable to those of smaller size forgings of 706 alloy(9). 
Table IV Tensile and impact properties at room temperature

\begin{tabular}{|c|cccc|c|}
\hline Locations & $\begin{array}{c}0.2 \% \mathrm{YS} \\
(\mathrm{MPa})\end{array}$ & $\begin{array}{c}\mathrm{TS} \\
(\mathrm{MPa})\end{array}$ & $\begin{array}{c}\mathrm{El} \\
(\%)\end{array}$ & $\begin{array}{c}\mathrm{RA} \\
(\%)\end{array}$ & $\begin{array}{c}\text { Absorbed Energy } \\
(\mathrm{J})\end{array}$ \\
\hline Rim & 1000 & 1248 & 19.0 & 30.6 & 82 \\
\hline Mid-radius & 1069 & 1238 & 16.0 & 22.4 & 49 \\
\hline Center & 1049 & 1235 & 14.5 & 16.6 & 53 \\
\hline $\begin{array}{c}\text { AMS's } \\
\text { spec. }\end{array}$ & $\geqq 931$ & $\geqq 1138$ & $\geqq 12$ & $\geqq 15$ & - \\
\hline
\end{tabular}
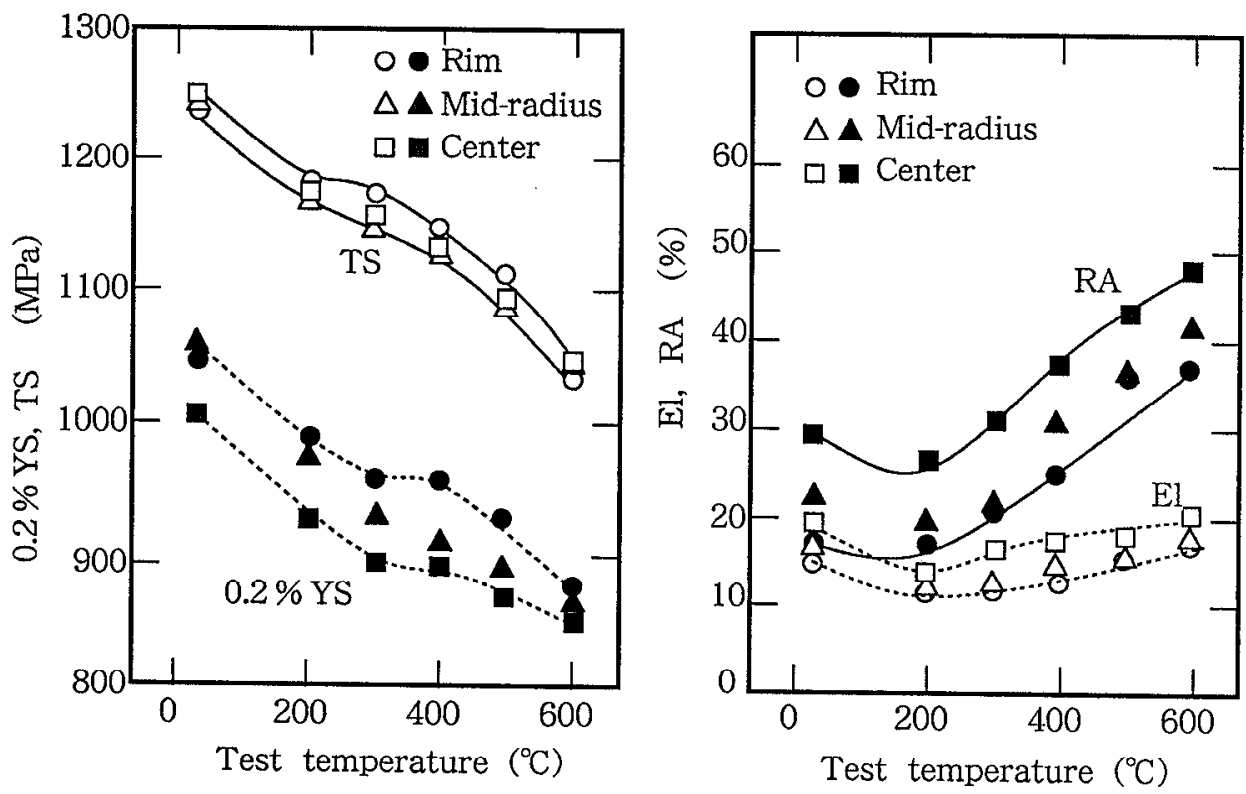

Figurte 7 Tensile properties of alloy 706 disk forging at various temperatures

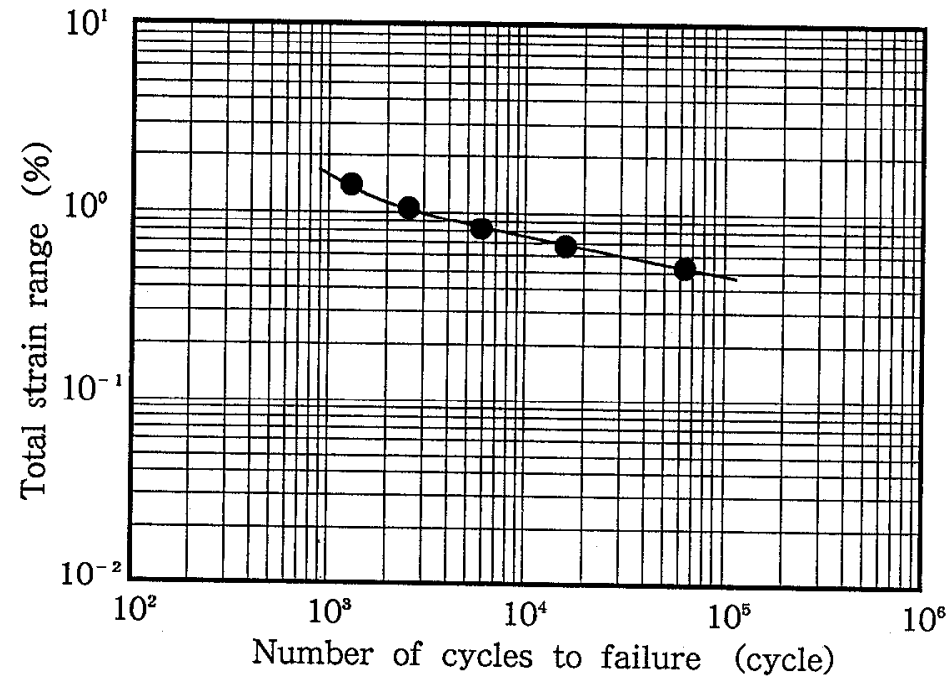

Figure 8 Low cycle fatigue properties at room temperature 


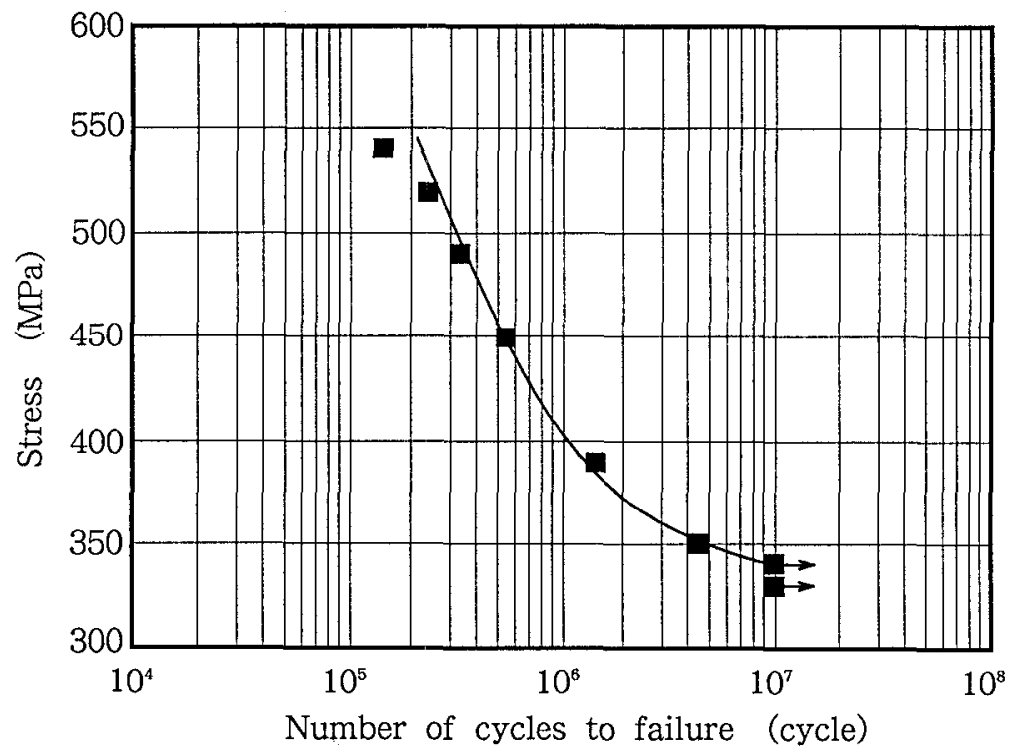

Figure 9 High cycle fatigue properties at room temperature

Table V Fracture toughness properties at room temperature

\begin{tabular}{|c|c|}
\hline & Fracture toughness \\
Loctions & $\mathrm{K}_{\mathrm{IC}}(\mathrm{J})(\mathrm{MPa} \sqrt{\mathrm{m}})$ \\
\hline Rim & 103 \\
\hline Mid-radius & 104 \\
\hline Center & 107 \\
\hline
\end{tabular}

\section{Summary}

Conditions of manufacturing nickel-base superalloy 706 disk were preliminary studied and a large trial disk was manufactured and evaluated.

The preliminary study results indicated that a good hot workability can be obtained in the temperatrue range of 850 to $1150{ }^{\circ} \mathrm{C}$, and a finer grain can be obtained through a combination of a lower heating temperature, a higher deformation of more than $20 \%$ and a controlled finish forging temperature just above $950{ }^{\circ} \mathrm{C}$ during the final forging process.

On the basis of the above results, a large trial disk $1900-\mathrm{mm}$ in diameter and $310-\mathrm{mm}$ in thickness was successfully forged from a 10tons electroslag remelted ingot with a $810-\mathrm{mm}$ diameter, and the internal quality and mechanical properties were evaluated. The results indicate that no macrosegregations and no defects were observed in the disk and the grain size was 3.2 3.8 in ASTM grain size number. The observed tensile properties met the requriement AMS 5703 specifications, and the fatigue and fracture toughness properties were equivalent to that of smaller size forgings of 706 alloy. 


\section{$\underline{\text { References }}$}

(1)P.W.Schilke et al.; "Advanced Materials propel progress in Land-based Gas Turbines", Advanced Materials and Processes, 4 (1992), 22 - 30

(2)D.Rayne \& J.F.Ugenet; "Fabrication of Large Components in 706 Alloy for Gas Turbine Application", 11th International Forgemaster Meeting Terni/Spoleto, Italy , 1991

(3)H.L.Eiselstein; "Properties of a Fabricable, High Strength Superalloy", Metals Engineering Quarterly, Nov.(1971), 20-25

(4)A.M.Johnson \& K.E.Fritz ; "The properties and Microstructure of Large Forged Superalloy Turbine Wheel", Superalloy :Metallurgy and Manufacture Proceedings of the 3rd international Symposium Sep. (1976), 12 - 5, Seven Springs, Pennsylvania

(5)G.D.Hooper et al.;'The use of Inconel Alloy 706 as a Structural Material in 300MVA Superconducting Generator", Advanced Cryogenic Engineering, Vol.30, (1984),359.

(6)O.Matsumoto et al ;"Mechanical Properties of Large Ni-base Superalloy Forging at Cryogenic temperatures." Published in International Cryngenic Materials Conference 1993

(7)Kobe Steel Ltd. unpublished work.

(8)J. D. Landes and J. A. Begley; In Fracture Analysis, ASTM STP. 560(1974), 170.

(9)W.A.logsdon et al. ; "Cryogenic Fracture Toughness and Fatigue Crack-Growth Rate Properties of Inconel 706 Base Materials and Gas Tungsten Arc Weldments", Advanced Cryogenic Engineering, Vol.26, (1984),137. 